\title{
Dashboards for Monitoring Congestion and Crashes in Interstate Work Zones
}

\author{
Michelle Mekker ${ }^{1}$, Howell Li² ${ }^{2}$ Ed Cox ${ }^{3}$, Darcy Bullock ${ }^{2}$ \\ ${ }^{1}$ Department of Civil and Environmental Engineering, Utah State University, Logan, UT, USA \\ ${ }^{2}$ School of Civil Engineering, Purdue University, West Lafayette, IN, USA \\ ${ }^{3}$ Indiana Department of Transportation, Indianapolis, IN, USA \\ Email: michelle.mekker@usu.edu, howell-li@purdue.edu, ecox@indot.in.gov,darcy@purdue.edu
}

How to cite this paper: Mekker, M., Li, H., Cox, E. and Bullock, D. (2019) Dashboards for Monitoring Congestion and Crashes in Interstate Work Zones. American Journal of Operations Research, 9, 15-30. https://doi.org/10.4236/ijg.2019.101003

Received: November 27, 2018

Accepted: January 19, 2019

Published: January 22, 2019

Copyright (c) 2019 by author(s) and Scientific Research Publishing Inc. This work is licensed under the Creative Commons Attribution International License (CC BY 4.0).

http://creativecommons.org/licenses/by/4.0/

\section{cc) (i) Open Access}

\begin{abstract}
Work zones present challenges to safety and mobility that require agencies to balance limited resources with vital traffic management activities. Extensive literature exists regarding the impact of congestion and recommendations for work zone design to provide safe and efficient traffic operations. However, it is often infeasible or unsafe to inspect every work zone within an agency's jurisdiction, so it is important to obtain operational feedback regarding congestion and crashes in work zones to prioritize inspection activities. This paper outlines the use of connected vehicle speed data and crash report data to identify operational performance problems in work zones. This is a way to provide feedback to queuing models used to design maintenance-of-traffic (MOT) plans. A weekly work zone report and dashboards were developed for use by the Indiana Department of Transportation (INDOT) for the purpose of assessing and improving both mobility and safety in work zones. The study has developed a mile-hours of congestion graph, frequency of speed delta heat map, congestion profile graph, and the Route Builder interactive application to comprehensively visualize work zone performance. This weekly report provides a mechanism for agency staff to maintain situational awareness of which work zones were most challenging for queues and during what periods those were likely to occur. In one case study, the reports were used to identify and mitigate operational performance problems in a work zone within 4 weeks, reducing congestion and crash rates. The integration of these data provided project managers with quantitative information about traffic mobility and performance of work zones for informed decision-making during the construction season.
\end{abstract}

\section{Keywords}

Work Zone, Congestion, Maintenance of Traffic, Construction, Queue 


\section{Introduction}

Maintenance of traffic (MOT) plans are an integral part of traffic operations for any roadway construction, maintenance, or rehabilitation project. The design of an MOT plan often occurs late in the design phase of a project (Figure 1). The process typically involves modeling to predict queue lengths and other impacts on mobility and safety. Most agencies with substantial interstate volumes have strict policies regarding the restriction of traffic on interstates to minimize queuing. Lane closures are often only allowed during certain hours or days with lower traffic volumes to minimize the formation of queues. However, estimating the lane capacity to calibrate a simulation model is a challenge for all states [1].

MOT plans implemented during construction may involve multiple stages depending on the schedule and scope of work activities. Ideally, traffic management personnel would monitor traffic and use the observed impacts to calibrate the queue models and/or make dynamic changes to the MOT plan as needed. However, with dozens of construction projects underway at any given time, monitoring work zones via regular in-person visits can consume significant manpower. Furthermore, work zones may have subtle changes on a near daily basis that can significantly impact work zone queueing. Indiana Department of Transportation (INDOT) policy states that the maximum allowable queue length is 1.5 miles [2].

The motivations for this work are as follows:

- Active monitoring of all active work zones within an agency's jurisdiction may not be feasible due to resource constraints;

- Work zone policies are often difficult to enforce due to lack of data;

- Models are often used to design MOT plans but are often difficult to validate without real data.

To assist INDOT in dynamic monitoring and assessment of interstate work zones, a weekly work zone report and web-based tools were developed, referred to as dashboards. A dashboard is a visual tool that allows the user to see the status of a system (or a part of a system) in a simple format, similar to how the dashboard of a car allows the driver to easily determine their speed and fuel level. Data from the dashboards give agencies leverage and actionable information to work with contractors on MOT adjustments and improvements.

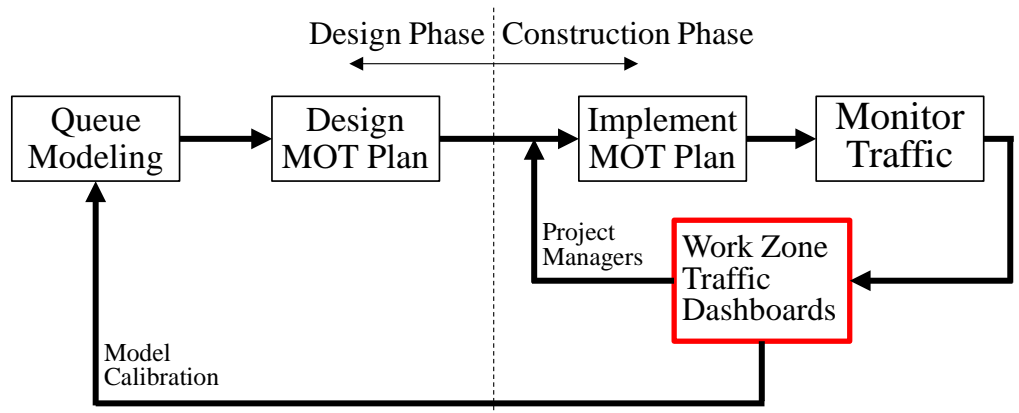

Figure 1. Work zone maintenance of traffic plan development flow chart. 
This paper reports on the development of a weekly work zone report and web-based dashboards to assist INDOT in dynamic monitoring and assessment of interstate work zones and maintenance of traffic plans within the state of Indiana. The contribution of this study is to utilize connected vehicle speed data to provide agencies with implementation-ready queue severity monitoring, dangerous speed differential, and integrated crash reporting tools to effectively manage resources for work zone traffic management.

The Federal Highway Administration (FHWA) published the Final Rule on Work Zone Safety and Mobility [1] in September of 2004. In short, this rule states that any roadway project receiving federal funds must have a maintenance of traffic plan. In response, many state and local agencies developed guidelines, policies, or programs for oversight of traffic management plans. The New York State Department of Transportation outlined clear contractual requirements, accident reporting, quality assurance/quality control procedures, etc. in its construction safety and health program [3]. The Virginia Department of Transportation developed its own Transportation Management Plan Requirements [4] based on recommendations published in 2005 [5]. These requirements apply to all projects within state right-of-way, regardless of funding source. In Washington, DC, a Citywide Transportation Management Plan was deployed to coordinate and analyze work zones and special events [6]. INDOT frequently updates its Interstate Highways Congestion Policy, which defines acceptable impacts on traffic, lane closure policy, etc. [2]. The purpose of these policies is to maintain capacity and reduce congestion due to work zones.

Evaluation and enforcement are critical in ensuring these policies are upheld and updated. Rouphail, Yang, and Fazio found significant "discrepancies between standards and practice" in their study of short- and long-term work zones [7]. In the work zones with such discrepancies, there were higher speed variations between vehicles. Gambatese and Johnson found that traffic management plans were of higher quality and had improved implementation when construction personnel were involved in the design phase and constructability was prioritized [8]. To manage compliance and quality, some agencies have developed quality assurance programs and inspection procedures [9]. Development and approval of maintenance of traffic plans often involve simulation [10] to assess mobility and safety impacts so effective work zone MOT plans can be designed. The Ohio Department of Transportation uses measured flow data to evaluate and calibrate their queue simulation programs [11].

Performance measures are an integral part of the monitoring and assessment of the impacts of MOT plans. Queue length, travel time, and delay are common performance measures [12] [13]. Bourne et al. [14] summarize some of the best practices in work zone assessment, data collection, and performance evaluation. The State of Virginia has its own performance assessment process [15]. Another study considered the effects of quantitative performance measures on the revision of the work zone decision-making process [16]. A common theme in all of these initiatives is that actively monitoring work zones and conducting af- 
ter-action assessment is important for continued improvement of traffic management and maintenance of traffic plans in the future.

While post-project assessment is important for future decision-making, active monitoring and dynamic management during the course of a work zone can reveal opportunities for improvement in mobility and safety. Real-time measurement of travel time delay can assist motorists in their decision to divert and avoid congestion and could be utilized for contracts with innovative travel time reliability clauses [17]. For example, the citywide work zone management and monitoring system developed for Washington DC, included a suite of web-based tools [5]. Work zone monitoring tools are valuable to agencies for the dynamic management of traffic at work zones.

\section{Data Sources}

This work utilized three data sources: work zone data, connected vehicle speed data, and crash data obtained from statewide crash report database. The following sections detail the nature and use of each data source in this research. Due to the nature of the US transportation system, English units are used as the primary units.

\subsection{Work Zone Data}

For the research presented in this paper, 18 work zones across Indiana were selected (Figure 2) and are a subset of the dynamic list of work zones monitored by these tools. The selected work zones ranged from 1 to 24 miles in length and included a variety of construction activities. INDOT personnel provide the data for and select all work zones based on expected congestion, publicity, and duration. The selected work zones are divided by INDOT district, route, direction, and start/end mile posts. The callouts in Figure 2 define the shorthand label used for each work zone in this paper. The first letter corresponds to the district. The number corresponds to the work zone's arbitrary order within that district. When discussing a particular direction of travel within the work zone, a second letter is added corresponding to the direction of travel. For example, a work zone labeled "C3S" corresponds to the southbound direction of the third work zone in the Crawfordsville district, which is on I-65 between mile posts 197 and 207.

\subsection{Connected Vehicle Data}

Connected vehicle speed data were collected from GPS devices, cellular phones, freight data, or vehicle telematics by a third-party vendor. These data came from $1 \%-2 \%$ of vehicles on interstates in Indiana. Individual vehicle trajectory data were aggregated as minute-by-minute space mean speeds for predefined road segments to preserve driver anonymity. The average road segment length was 0.88 miles. In Indiana, there were approximately 2600 segments covering all of the 2250 directional miles of interstate. Each data point had a timestamp, location, 


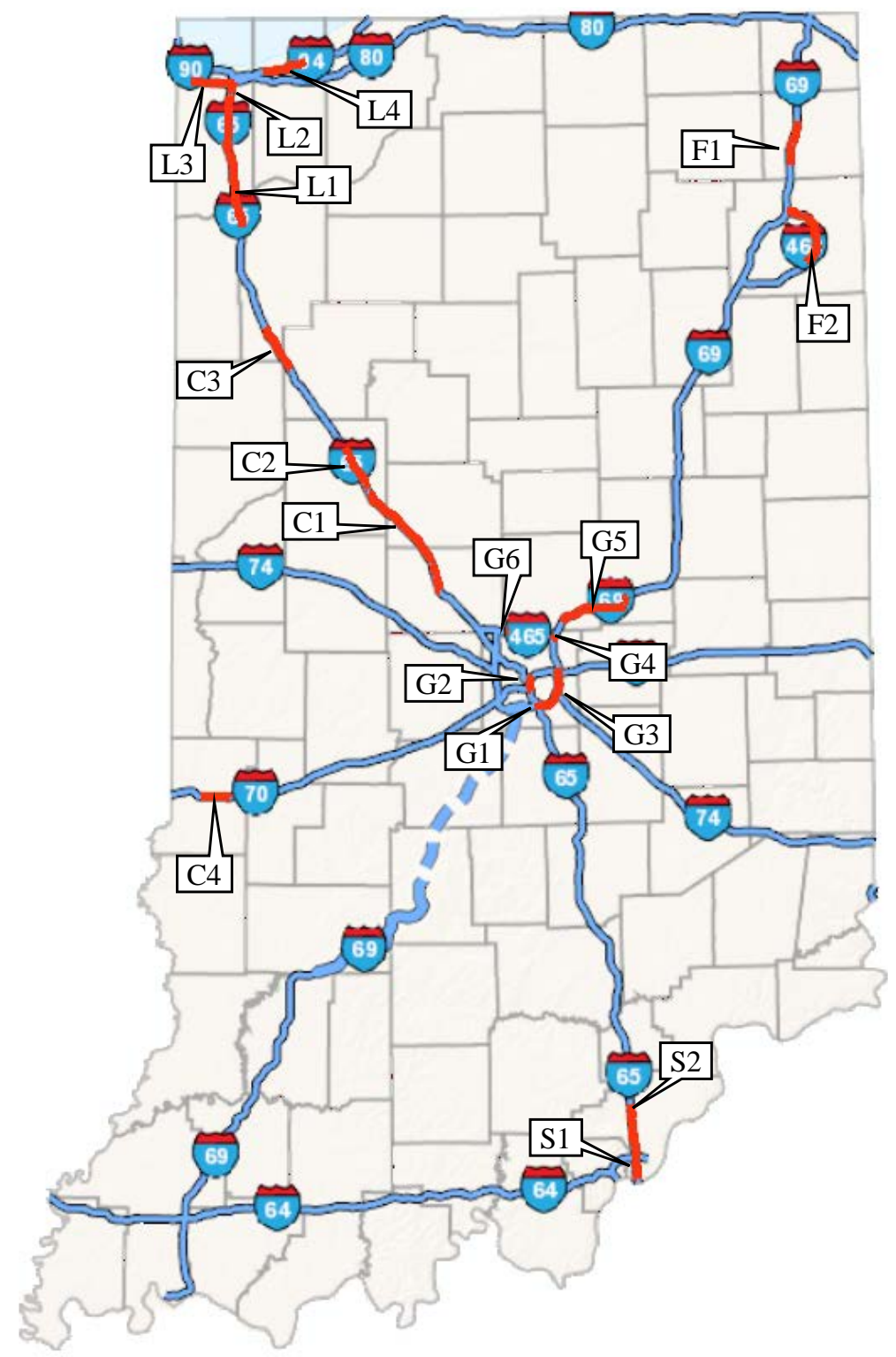

Figure 2. Map of selected work zones.

speed, and confidence level. These data were used in place of traditional traffic count stations or cameras due to the significantly larger area of coverage.

Using these data, performance measures have been created that visually depict the performance of an entire roadway over a period of time. These data have been used for performance measures in Indiana in the Indiana Mobility Report [18] and nationwide in the Urban Mobility Scorecard [19]. In Indiana, performance measures for decision-makers were developed using these data [20]. These data have also been used for real-time traffic monitoring [21], in which there is a lag of 3 - 5 minutes.

\subsection{Crash Data}

Crash data were retrieved from the state crash database and used to supplement 
the connected vehicle data. Only crashes that occurred on an interstate in Indiana were used in this study. Personal information about the crash participants and investigating officers, such as names and license plate numbers, were not included in these data. These data did include the following relevant information for each crash: date/time, location, number of injuries/fatalities, primary factor, and manner of collision.

\section{Reports and Dashboards}

The work zone reports and associated dashboards have been in use by INDOT since May 2016. The components of the report are compiled into a slide deck and distributed to INDOT traffic and project managers. The components are constructed using a mix of database queries, spreadsheets, and dashboards. Each of the report components will be covered in detail in the following subsections.

\subsection{Mile-Hours of Congestion}

Mile-hours of congestion is a performance metric that combines the number of hours a segment of roadway $i$ belonging to a section $S$ is operating under a critical threshold $v_{c}$, and the length of the segment $l_{i}$. The mile-hours of congestion $C$ is calculated using Equation (1).

$$
C=\frac{\sum_{i \in S} \sum_{j \in T} \begin{cases}l_{i} & v_{i j}<v_{c} \\ 0 & v_{i j} \geq v_{c}\end{cases} }{60}
$$

The time interval $j$ belongs to analysis period $T$, provided in 1-minute frequency. In this study the critical threshold used is $45 \mathrm{mph}$.

Figure 3, the first page of the report for a work zone, includes two plots of mile-hours by day, one for each direction. A mile-hour is a measure of congestion that is temporally and spatially weighted and based on the average operating speed from the connected vehicle data. Each column in the graph represents the total number of mile-hours of operation within each speed bin in one day within the work zone. It does not include the congestion that extends or occurs outside of the work zone. These plots allow personnel to view overall performance and quickly identify days or weeks that had more severe congestion. The 4 weeks prior to the current week are included to provide context and to show any emerging trends.

Also included in the work zone report is a summary of the total congestion observed in the INDOT district. In the district-wide view, there are three different mile-hour graphs: the sum of all congestion by speed in the work zones within that district, the sum of all congestion by work zone within that district, and the total congestion on all interstate segments within the district. This view is particularly useful for district managers. The impact of district- or region-wide events, such as weather or holidays, within work zones and the entire district can be observed. Patterns of congestion within the work zone that are also observed within the district can be more easily attributed to non-work zone factors. 


\section{C4: I-70 Vigo}

(B-31192)

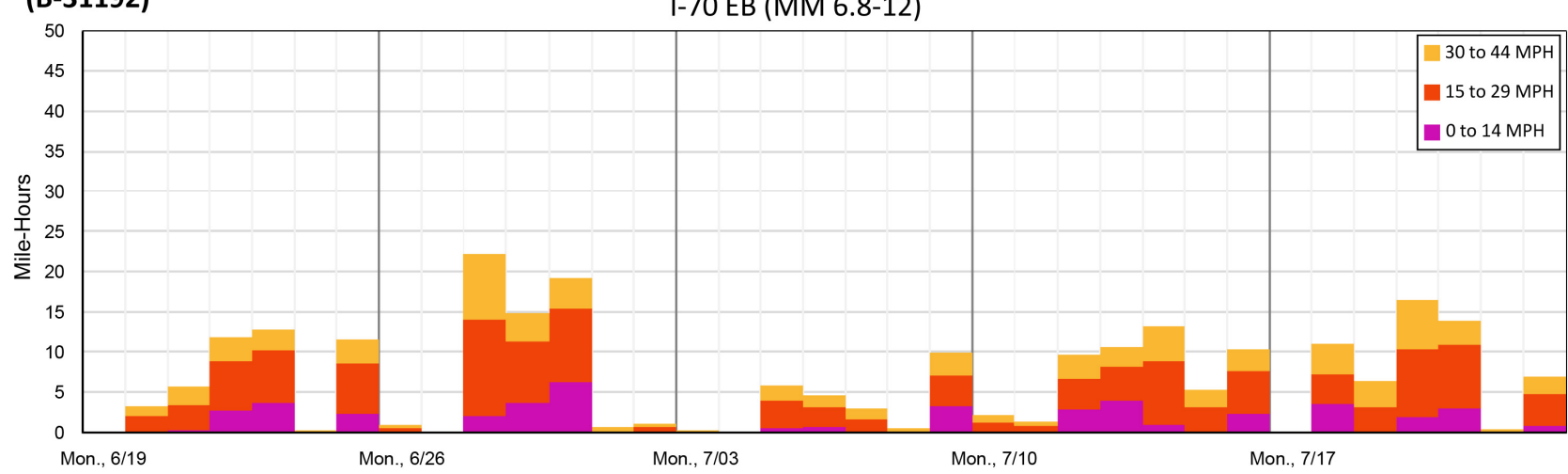

I-70 WB (MM 6.8-12)

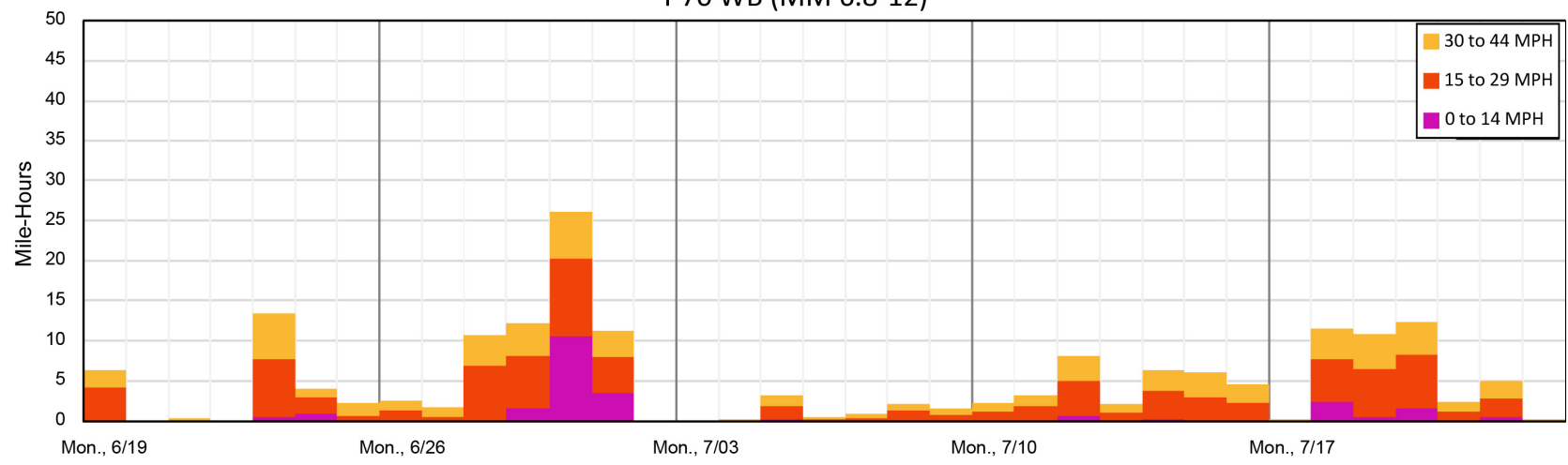

Figure 3. Work zone mile-hours of congestion plots.

INDOT personnel currently have access to a web-based dashboard that generates these figures automatically based on customizable work zone inputs.

\subsection{Frequency of Speeddelta}

Figure 4, the second page of the report for a work zone, includes two heat maps of speeddelta frequency by day and longitudinal location. The speeddelta is the difference between the average speeds of two adjacent connected vehicle reporting segments. If vehicles are decelerating, the speeddelta will be positive (upstream speed minus downstream speed). In this plot, a threshold of speeddelta greater than or equal to $15 \mathrm{MPH}$ is used so as to eliminate noise from minor changes in speed. Due to the nature of the connected vehicle data segmentation, each horizontal line in the grid represents the point between two adjacent segments. The distance between these points are not to scale in these plots. The darker colored spots represent locations where vehicles slowed down more frequently during that day.

\subsection{Congestion Profile}

The third component of the report for a work zone includes two congestion profiles for the work zone in the current week (Figure 5). The congestion profile was developed as part of the Indiana Mobility Report [18]. These plots include 


\section{C4: I-70 Vigo \\ (B-31192)}

Frequency* (minutes) $\square$ 0-30 $\square$ 30-60 $\square$ 60-90 $\square$ 90-120 $\square$ 120-150 $\square$ 150-180 $\square>180$

*Only counting speeddelta $\geq 15 \mathrm{MPH}$

Frequency of Speeddelta Occurrence within Work Zone

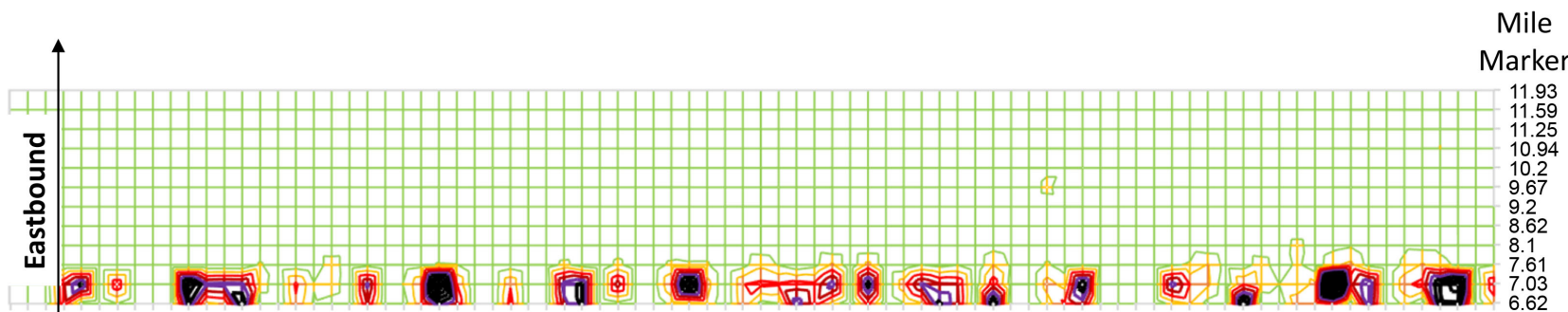

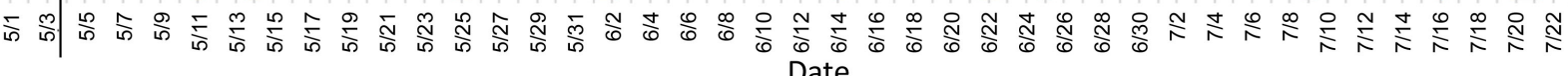

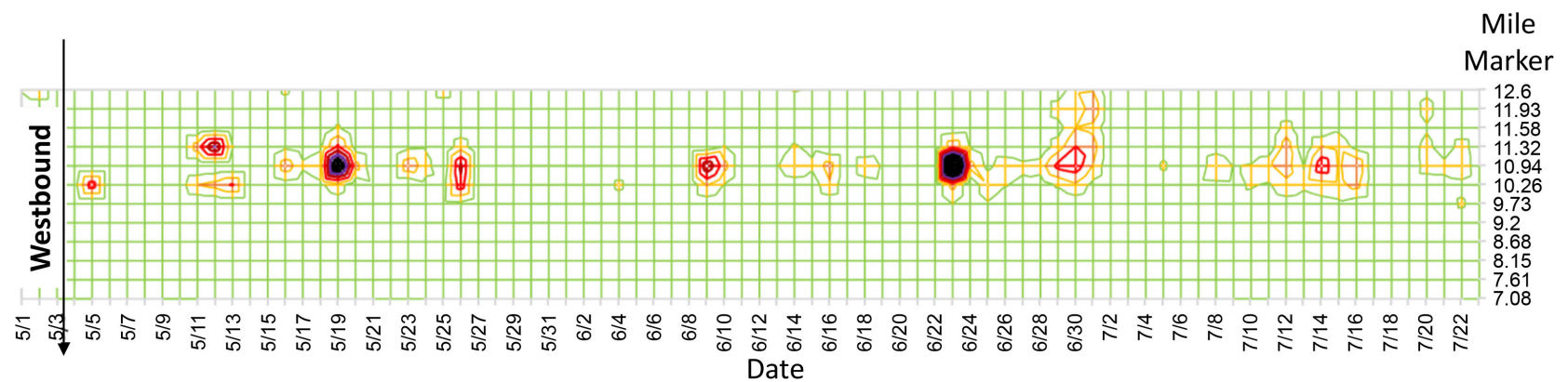

Figure 4. Work zone frequency of speeddelta plots.

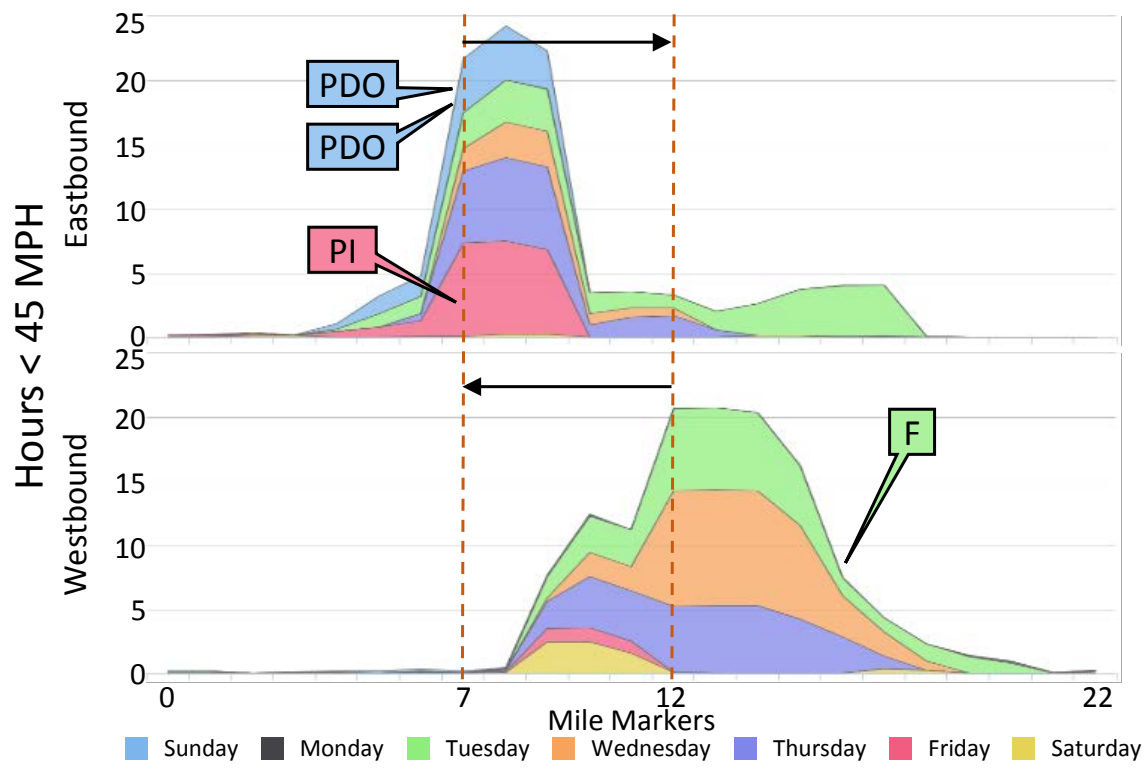

Figure 5. Work zone congestion profiles.

both the work zone (boundaries delineated by the orange dashed lines) and up to 10 miles upstream and downstream of the work zone. The congestion profile shows the hours of congestion (default threshold for interstate congestion is 45 MPH) by mile post and by day (represented by different bands of color). It is a useful longitudinal representation of congestion within and around the work 
zone. Significant traffic incidents with large queues are typically represented by a wide band of color corresponding to the day of the incident. Stacked bands of similar width typically represent recurring congestion at a particular location. Crashes during the week are called out on the plots by mile marker location and day (color). The severity of the crash is denoted in the callout as property damage only (PDO), personal injury (PI), or fatality (F).

INDOT personnel currently have access to a web-based dashboard that generates these figures automatically based on customizable work zone inputs.

\subsection{Summary Table}

Table 1 shows a summary table, the fourth component, for the current week. In addition to columns containing information about the work zone and location, this tables includes the following columns:

- Queueing $\geq 5 \mathrm{mi}(\mathrm{hr})$ : number of hours when there was a queue of length greater than or equal to 5 miles within or overlapping the work zone. This is a good measure of the duration of severe traffic incidents.

- Queueing upstream of $W Z(h r)$ : number of hours when there was a queue extending upstream of the work zone boundary. This measure is important to traffic and project managers in regard to the placement of advance warning signs and queue length modeling.

- Mile-hours < 45 MPH (week): mile-hours of congestion in the work zone for the whole week. This measure is useful in comparison to previous weeks.

- Mile-hours < $45 \mathrm{MPH}$ (worst day): mile-hours of congestion in the work zone for the "worst" day. This measure is useful for determining the impact of recurring congestion relative to individual incidents.

- PDO Crashes: number of property-damage-only crashes within the work zone.

- PI Crashes: number of personal injury crashes within the work zone. Fatal crashes, due to their rarity, are included in this number but are called out in the table with an "*" and in the notes.

- BOQ Crashes: number of back-of-queue crashes within or upstream of the work zone. A back-of-queue crash is a crash that occurs at a shockwave boundary of a queue that exists within or overlaps with the work zone.

\subsection{Route Builder}

The previous sections discuss aggregate measures and visualizations of the congestion within the work zone. However, it is often useful to view the data in an

Table 1 . Work zone summary table.

\begin{tabular}{|c|c|c|c|c|c|c|c|c|c|c|c|c|}
\hline Work Zone & Date Range & Route & $\begin{array}{c}\text { Mile } \\
\text { Marker }\end{array}$ & Direction & $\begin{array}{l}\text { Queueing } \\
\geq 5 \mathrm{mi}(\mathrm{hr})\end{array}$ & $\begin{array}{l}\text { Queueing } \\
\text { upstream of } \\
\text { WZ (hr) }\end{array}$ & $\begin{array}{c}\text { Mile-hours } \\
<45 \mathrm{MPH} \\
\text { (week) }\end{array}$ & $\begin{array}{c}\text { Mile-hours } \\
<45 \mathrm{MPH} \\
\text { (worst day) }\end{array}$ & $\begin{array}{l}\text { Worst } \\
\text { Day }\end{array}$ & $\begin{array}{c}\text { PDO } \\
\text { Crashes }\end{array}$ & $\begin{array}{c}\text { PI } \\
\text { Crashes }\end{array}$ & $\begin{array}{c}\text { BOQ } \\
\text { Crashes }\end{array}$ \\
\hline \multirow{2}{*}{$\begin{array}{c}\mathrm{C} 4 \\
(\mathrm{~B}-31192)\end{array}$} & \multirow{2}{*}{$7 / 17-7 / 23$} & \multirow{2}{*}{$\mathrm{I}-70$} & \multirow{2}{*}{6.8 to 12} & $\mathrm{E}$ & 0.93 & 0.98 & 54.78 & 16.43 & Th & 2 & 1 & 3 \\
\hline & & & & $\mathrm{W}$ & 12.68 & 28.68 & 42.32 & 12.41 & Th & 0 & $1^{*}$ & 1 \\
\hline
\end{tabular}


unaggregated manner. Figure 6 shows the final component of the work zone report. Each direction has two graphs: total queue length ("Total Queue Length over Area of Analysis vs. Time") and the queue heat map ("Queues by Mile Markers vs. Time"). The total queue length graphs are useful to traffic managers for comparing predicted to actual queue lengths. The two directions, placed side by side, can also be easily compared. The crashes counted in the Table 1 are called out on the queue heat maps in Figure 6 using the same severity abbreviations as the congestion profiles (Figure 5).

INDOT personnel currently have access to a web-based dashboard that generates these figures automatically based on customizable work zone inputs.

\section{Implementation}

The weekly work zone reports and dashboards have already provided and will continue to provide INDOT traffic management personnel with valuable information. As stated above, the work zone reports have been actively used since May 2016. The list of work zones included in the work zone report changes dynamically. As of November 2019, the reports are distributed weekly to more than 40 INDOT personnel and Indiana State Police officers.

\section{C4: I-70 Vigo}

(B-31192)
35-44 mph $25-34 \mathrm{mph} \quad 15-24 \mathrm{mph}$ 5-14 mph 0-4 mph

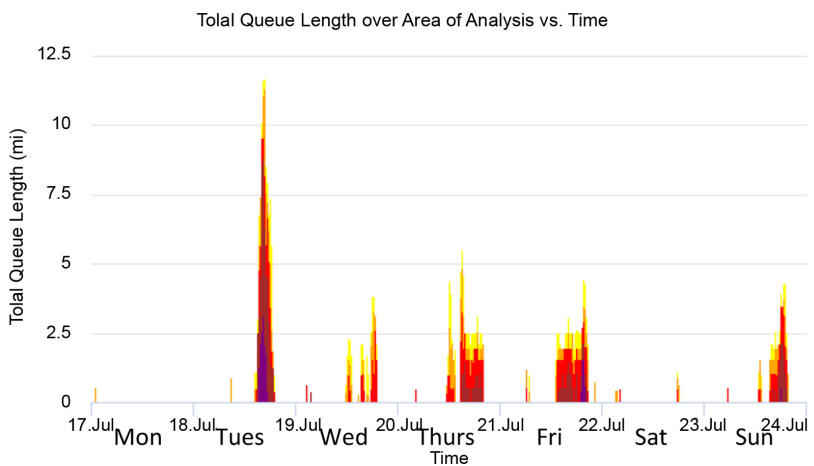

80

Tolal Queue Length over Area of Analysis vs. Time
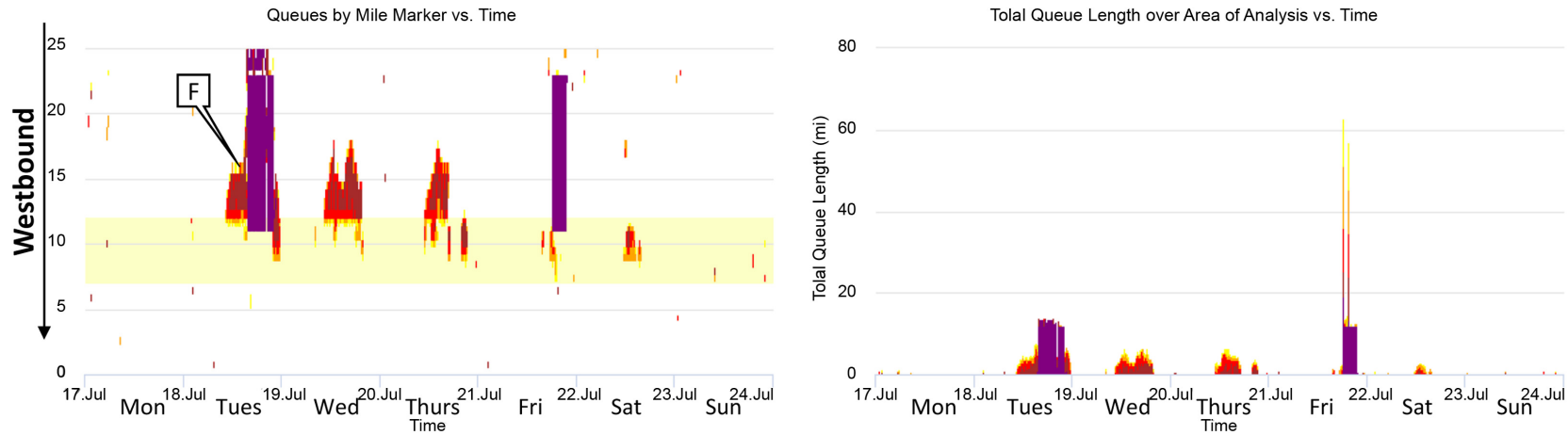

Figure 6. Work zone queue heat maps and queue length plots. 
One case study demonstrating the application of the work zone report occurred during July-August of 2016 in the C2S work zone (I-65 SB, mile markers 167 - 176). Figure 7(a) shows that in the week of July 4, recurring congestion in the work zone increased compared to the previous weeks. Also at this time, there was a $185 \%$ increase in crashes per week. These changes were quickly noted in the weekly work zone report and a visual inspection of the work zone was conducted. It was found that the congestion and crashes corresponded to three locations: a lane divergence point at mile marker 176 (Figure 8(a)), an on-ramp at mile marker 175, and a lane convergence at mile marker 173 (Figure 8(b)). Sharp reverse curves existed at the lane divergence and convergence points.

After the inspection, recommendations were provided to the project manager and implemented. These recommendations included increased signage at the on-ramp and discouragement of lane change/drift with drums and lane markings at the reverse curves. After the changes were implemented in the work zone, the recurring congestion at that location was mitigated (Figure 7 (b)) and crashes per week decreased by $47 \%$. The time between identification and mitigation of the problem was 4 weeks.

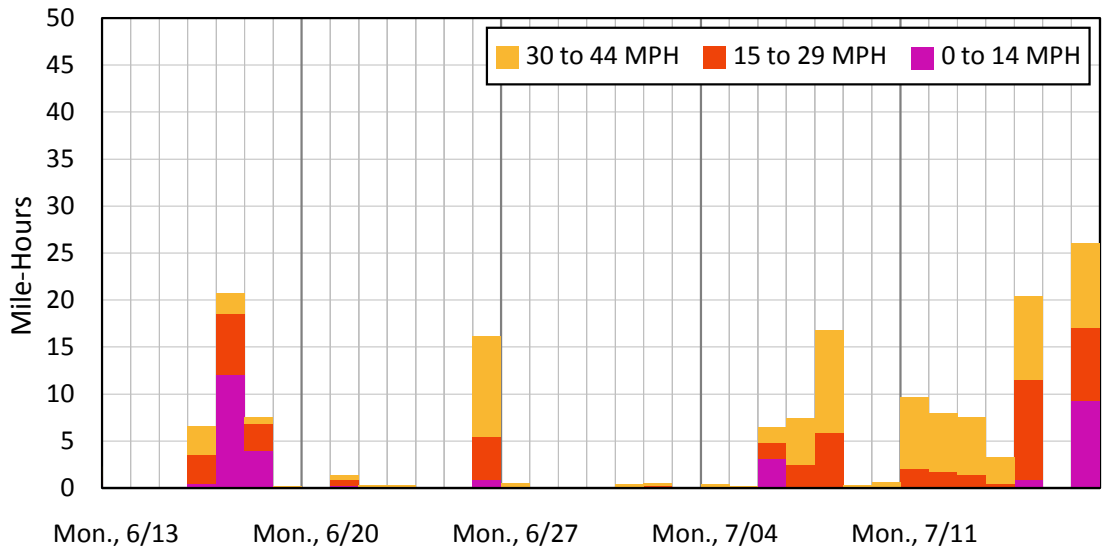

(a)

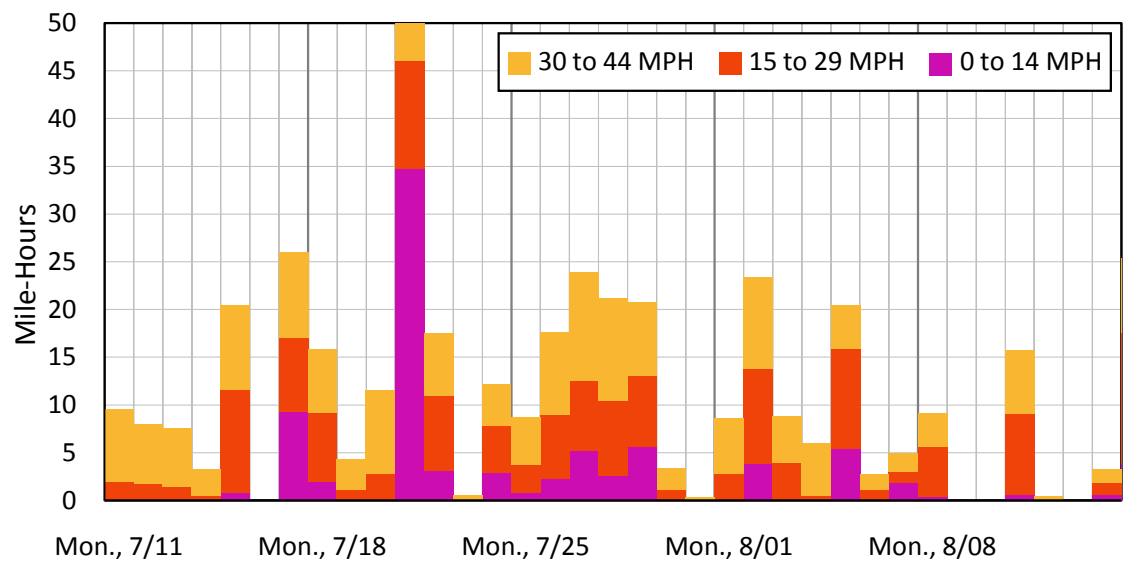

(b)

Figure 7. Mile-hours of congestion for C2S work zone on I-65 (mile marker 167-176). (a) 6/13/16-7/17/16; (b) 7/11/16-8/14/16. 


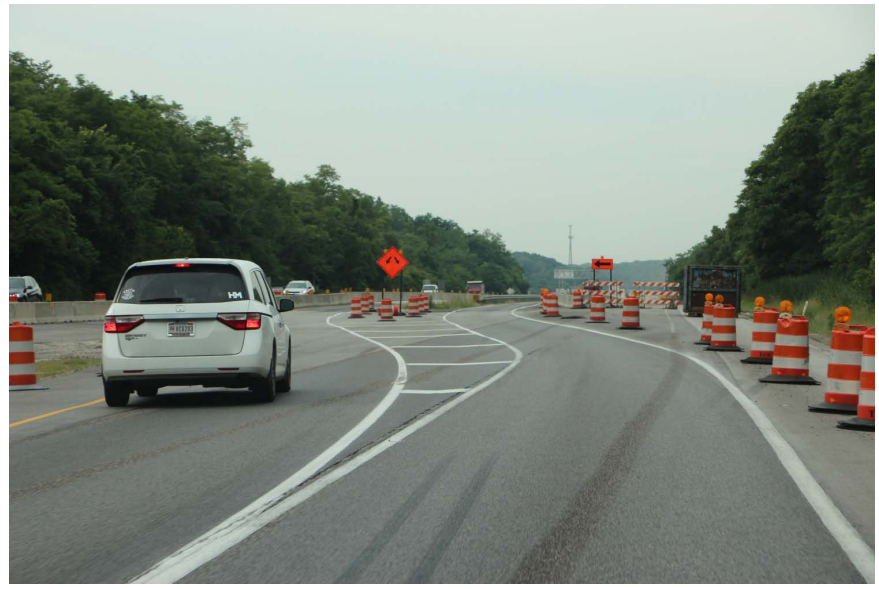

(a)

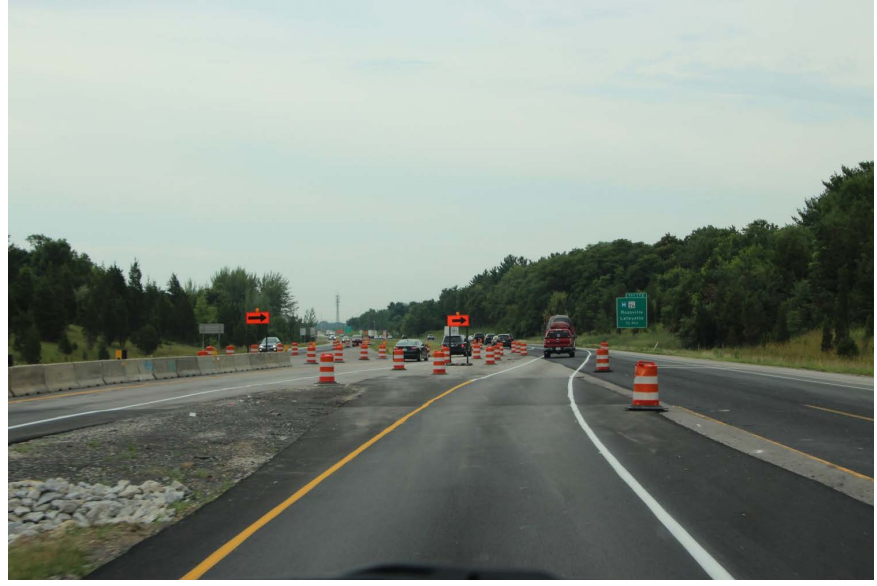

(b)

Figure 8. Reverse curves in the C2S work zone on I-65 (mile marker 167-176). (a) Lane divergence at mile marker 176; (b) Lane convergence at mile marker 173.

The dashboards were developed for traffic managers to customize and monitor a more selective or different list of work zones. The dashboards allow users to view different time periods that may not fall within the typical week of the work zone report. The most recent dashboard was made available to INDOT in May 2018.

Active monitoring of work zones using these tools allow for more efficient use of time and resources. Managers can make informed decisions regarding the deployment of assets, enforcement, or the disbursement of information to the public. For example, INDOT policy [6] states that the maximum allowable queue length is 1.5 miles. Table 2 summarizes data from the work zone reports for 5 months (April-August) in the 2017 construction season. These reports can be and have been used to highlight work zones that are underperforming in regards to mobility and traffic operations.

\section{Conclusions}

Connected vehicle data and crash data were utilized to develop a weekly work 
Table 2. 5-month work zone queueing summary table.

\begin{tabular}{|c|c|c|c|}
\hline Work Zone & $\begin{array}{c}\text { Hours of } \\
\text { Queueing }>1.5 \text { miles }\end{array}$ & $\begin{array}{l}\text { Maximum Observed } \\
\text { Queue Length (miles) }\end{array}$ & $\begin{array}{l}\text { Median Observed Queue } \\
\text { Length (miles) }\end{array}$ \\
\hline $\mathrm{C} 1 \mathrm{~N}$ & 154.12 & 4.49 & 1.75 \\
\hline $\mathrm{C} 1 \mathrm{~S}$ & 186.85 & 8.87 & 1.90 \\
\hline $\mathrm{C} 2 \mathrm{~N}$ & 85.50 & 11.70 & 1.75 \\
\hline $\mathrm{C} 2 \mathrm{~S}$ & 62.29 & 7.30 & 2.44 \\
\hline $\mathrm{C} 3 \mathrm{~N}$ & 47.41 & 5.48 & 0.82 \\
\hline $\mathrm{C} 3 \mathrm{~S}$ & 42.76 & 4.74 & 1.08 \\
\hline C4E & 294.39 & 7.69 & 1.57 \\
\hline $\mathrm{C} 4 \mathrm{~W}$ & 196.48 & 22.47 & 2.08 \\
\hline F1N & 62.69 & 8.51 & 1.63 \\
\hline F1S & 31.06 & 11.76 & 1.24 \\
\hline $\mathrm{F} 2 \mathrm{~N}$ & 32.41 & 5.25 & 0.90 \\
\hline F2S & 14.77 & 5.68 & 0.60 \\
\hline G1N & 6.34 & 4.02 & 0.87 \\
\hline G1S & 80.13 & 9.68 & 1.18 \\
\hline $\mathrm{G} 2 \mathrm{~N}$ & 49.38 & 7.73 & 0.98 \\
\hline G2S & 18.85 & 5.86 & 1.21 \\
\hline G3IL & 123.19 & 11.53 & 1.55 \\
\hline G3OL & 29.77 & 14.40 & 1.15 \\
\hline G4N & 0 & 0.84 & 0.39 \\
\hline G4S & 55.27 & 10.68 & 1.31 \\
\hline G5N & 166.53 & 10.68 & 1.86 \\
\hline G5S & 110.93 & 7.91 & 1.28 \\
\hline G6IL & 75.01 & 5.43 & 2.63 \\
\hline G6OL & 16.37 & 7.05 & 0.60 \\
\hline L1N & 38.68 & 6.58 & 1.81 \\
\hline L1S & 31.35 & 9.97 & 1.10 \\
\hline L2N & 55.77 & 5.32 & 0.77 \\
\hline L2S & 77.80 & 4.60 & 1.47 \\
\hline L3E & 309.67 & 10.80 & 2.48 \\
\hline L3W & 715.03 & 21.90 & 1.93 \\
\hline $\mathrm{L} 4 \mathrm{E}$ & 150.44 & 14.09 & 1.77 \\
\hline L4W & 150.37 & 6.28 & 0.02 \\
\hline S1N & 0.66 & 2.49 & 0.68 \\
\hline S1S & 16.54 & 7.62 & 1.14 \\
\hline S2N & 15.38 & 8.99 & 1.15 \\
\hline S2S & 49.69 & 10.50 & 2.08 \\
\hline
\end{tabular}


zone report and dashboards to identify operational performance problems in work zones. The integration of these data provided project managers with quantitative information about traffic mobility and performance of work zones that enabled informed decision-making. With the web-based dashboards, agencies were able to leverage the weekly work zone reports for active and after-action monitoring. Prior to the development of these reports and dashboards, it was infeasible for INDOT to inspect every work zone within their jurisdiction. The reports allowed traffic managers to monitor queue lengths to determine if work zone congestion exceeded policy limits. The study determined:

1) Workzone inspection was more efficient as a result of using connected vehicle data for queue reporting. During the 2017 construction season, 36 workzones were monitored using the tools developed;

2) In a five-month period, queueing greater than the congestion policy limit of 1.5 miles was observed for a total of 1923 hours;

3) The maximum observed queue length using the developed methods in this study was 22.5 miles in the $\mathrm{C} 4 \mathrm{~W}$ work zone. Previously this was very difficult to ascertain;

4) One case study demonstrated how the reports were used to identify and mitigate operational performance problems in a work zone within 4 weeks. The recommended adjustments due to the report and subsequent inspection resulted in a $47 \%$ reduction in crashes per week and a reduction of recurring congestion in the work zone.

With these data, informed decisions were made regarding necessary action, such as recalibration of queue models, changes to policy, or alteration of the work zone layout. The operational performance of work zones was monitored to identify when changes, such as drum placement, have an adverse impact on queueing and safety. The reports also provided factual information to public information officers to communicate to the media regarding queue lengths, peak periods, and recovery after crashes.

Future work with this topic includes feeding the congestion data developed in this study back into queuing models to improve the design and modeling during the MOT planning process in future seasons. In addition, more robust, interactive and automated workzone reporting to supervisors can be integrated with departments of transportation's systems to provide advanced features such as district-level performance rankings, characterizing and inventorying workzone assets and geometries, and real-time text alerting. Other data sources such as high-fidelity weather data can also be included to provide greater texture to describe congestion impacts, such as isolated flooding and wind.

\section{Acknowledgements}

This work was supported by the Joint Transportation Research Program administered by the Indiana Department of Transportation and Purdue University. The connected vehicle data was provided by INRIX. The contents of this paper 
reflect the views of the authors, who are responsible for the facts and the accuracy of the data presented herein, and do not necessarily reflect the official views or policies of the sponsoring organizations. These contents do not constitute a standard, specification, or regulation.

\section{Conflicts of Interest}

The authors declare no conflicts of interest regarding the publication of this paper.

\section{References}

[1] Federal Highway Administration (2004) Final Rule on Work Zone Mobility and Safety. Federal Highway Administration, Washington DC.

[2] Indiana Department of Transportation (2017) Interstate Highways Congestion Policy. Indiana Department of Transportation, Indianapolis, IN.

[3] Andrew, L.B. and Bryden, J.E. (1997) Managing Construction Safety and Health: Experience of New York State Department of Transportation. Transportation Research Record, 1585, 9-18. https://doi.org/10.3141/1585-02

[4] Virginia Department of Transportation (2009) Transportation Management Plan Requirements. Virginia Department of Transportation, Richmond, VA.

[5] Cottrell, B. (2005) Guidelines for Developing Transportation Management Plans in Virginia. Virginia Department of Transportation, Charlottesville, VA.

[6] Dickerson, C., Wang, J., Witherspoon, J. and Crumley, S. (2016) Work Zone Management in the District of Columbia: Deploying a Citywide Transportation Management Plan and Work Zone Project Management System. Transportation Research Record, 2554, 37-45. https://doi.org/10.3141/2554-05

[7] Rouphail, N.M., Yang, Z.S. and Fazio, J. (1988) Comparative Study of Short- and Long-Term Urban Work Zones. Transportation Research Record, 1163, 4-14.

[8] Gambatese, J. and Johnson, M. (2014) Impact of Design and Construction on Quality, Consistency, and Safety of Traffic Control Plans. Transportation Research Record, 2458, 47-55. https://doi.org/10.3141/2458-06

[9] Bryden, J.E. and Andrew, L.B. (2001) Quality Assurance Program for Work Zone Traffic Control. Transportation Research Record, 1745, 1-9. https://doi.org/10.3141/1745-01

[10] Collura, J., Heaslip, K., Moriarty, K., Wu, F., Khanta, R. and Berthaume, A. (2010) Simulation Models for Assessment of the Impacts of Strategies for Highway Work Zones: Eight Case Studies along Interstate Highways and State Routes in New England. Transportation Research Record, 2169, 62-69. https://doi.org/10.3141/2169-07

[11] Schnell, T., Mohror, J. and Aktan, F. (2002) Evaluation of Traffic Flow Analysis Tools Applied to Work Zones Based on Flow Data Collected in the Field. Transportation Research Record, 1811, 57-66. https://doi.org/10.3141/1811-07

[12] Chitturi, M. and Benekohal, R. (2013) Work Zone Queue Length \& Delay Methodology. Transportation Letters. The International Journal of Transportation Research, 2, 273-283. https://doi.org/10.3328/TL.2010.02.04.273-283

[13] Pesti, G. and Brydia, R. (2017) Work Zone Impact Assessment Methods and Applications. Transportation Research Record, 2617, 52-59.

https://doi.org/10.3141/2617-07

[14] Bourne, J., Eng, C., Ullman, G., Gomez, D., Zimmerman, B., Scriba, T., Lipps, R., 
Markow, D., Matthews, K., Holstein, D. and Stargell, R. (2010) Best Practices in Work Zone Assessment, Data Collection, and Performance Evaluation. NCHRP Project 20-68A, Transportation Research Board, Washington DC.

[15] Gallo, A., Dougald, L. and Demetsky, M. (2013) Formalized Process for Performance Assessment of Work Zone Transportation Management Plans in Virginia. Transportation Research Record, 2337, 50-58. https://doi.org/10.3141/2337-07

[16] Hartmann, T. and Hawkins Jr., H. (2009) Revised Process for Work Zone Decision Making Based on Quantitative Performance Measures. Transportation Research Record, 2107, 14-23. https://doi.org/10.3141/2107-02

[17] Haseman, R., Wasson, J. and Bullock, D. (2010) Real-Time Measurement of Travel Time Delay in Work Zones and Evaluation Metrics Using Bluetooth Probe Tracking. Transportation Research Record, 2169, 40-53. https://doi.org/10.3141/2169-05

[18] Day, C., McNamara, M., Li, H., Sakhare, R., Desai, J., Cox, E., Horton, D. and Bullock, D. (2016) 2015 Indiana Mobility Report and Performance Measures. Indiana Mobility Reports, Joint Transportation Research Program, West Lafayette. https://doi.org/10.5703/1288284316352

[19] Schrank, D., Eisele, B., Lomax, T. and Bak, J. (2015) 2015 Urban Mobility Scorecard. The Texas A\&M Transportation Institute and INRIX, College Station.

[20] Brennan, T., Remias, S., Grimmer, G., Horton, D., Cox, E. and Bullock, D. (2013) Probe Vehicle-Based Statewide Mobility Performance Measures for Decision Makers. Transportation Research Record, 2338, 78-90. https://doi.org/10.3141/2338-09

[21] Li, H., Remias, S., Day, C., Mekker, M., Sturdevant, J. and Bullock, D. (2015) Shockwave Boundary Identification Using Cloud-Based Probe Data. Transportation Research Record, 2526, 51-60. https://doi.org/10.3141/2526-06 